MATEC Web of Conferences 3, 01036 (2013)

DOI: $10.1051 /$ matecconf/20130301036

(C) Owned by the authors, published by EDP Sciences, 2013

\title{
Stability of solid phases in the dexamathasone acetate/water system
}

\author{
S. Delage, N. Couvrat, M. Sanselme, Y. Cartigny, and G. Coquerel
}

Laboratoire SMS, Université de Rouen, Rouen, France

\section{Introduction}

Dexamethasone acetate (9 $\alpha$-fluoro-16 $\alpha$-methyl11ß,17,21-trihydroxy-1,4-pregnadiene-3,20-dione 21acetate, DMA hereafter) (Fig 1) is an active pharmaceutical ingredient frequently used as an antiinflammatory against rheumatism pains, asthma or even cancer pains.

This molecule presents an original behavior during its crystallization in specific conditions. For example, an ethanolic saturated solution of DMA injected in water (anti-solvent) [1] leads to the formation of hollow needlelike crystals called whiskers. At present, the mechanism of formation of these "whiskers" remains not fully understood $[1,2]$.

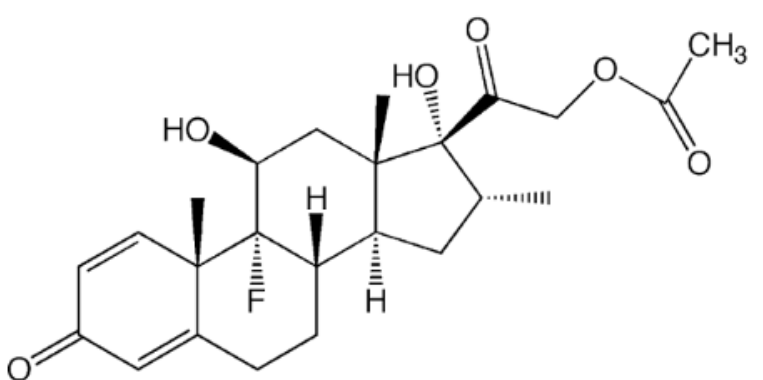

Figure 1. Complete solid-liquid equilibrium diagram of water(1) + acetic acid(2) calculated from the PC-SAFT EoS.

In order to understand the mechanism of crystallization, it was first decided to characterize the solid phases of DMA in water.

\section{Experimental}

Previous studies indicated that in aqueous solution, DMA can crystallize as a monohydrated $\left(1 \mathrm{H}_{2} \mathrm{O}\right)$ or a sesquihydrated $\left(1,5 \quad \mathrm{H}_{2} \mathrm{O}\right)$ phase. Moreover, two anhydrous polymorphic forms (Form I and II) are known. The stability of DMA solid phases were investigated with the help of X-Ray powder diffraction under variable temperature and relative humidity [3], single crystal XRay diffraction, Dynamic Vapor Sorption [4-6] and TGDSC.

\section{Results}

\subsection{Thermal beahaviour}

The two anhydrous polymorphic forms (Form I and II) are monotropically related and Form I is the stable phase (figure 2)

No transition from sesquihydrate to monohydrate could be induced by heating.

Starting from hydrated form (monohydrate and sesquihydrate are obtained in water or in water/solvent mixtures), the thermal dehydration of the two phases leads to the crystallization of form II before the monotropic transition into form I at high temperature (Figure 3). 


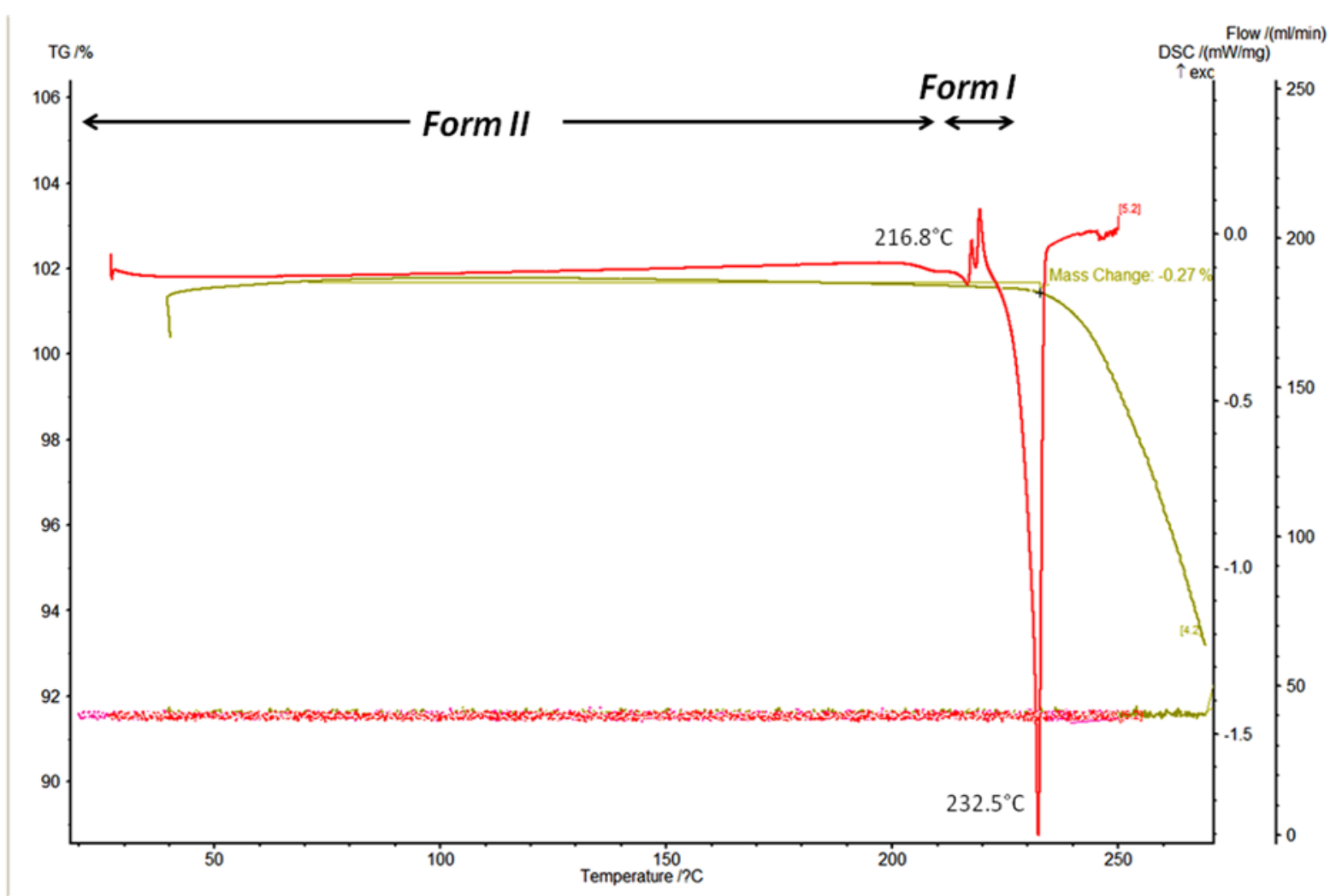

Figure 2. TG-DSC obtained on DMA Form II.

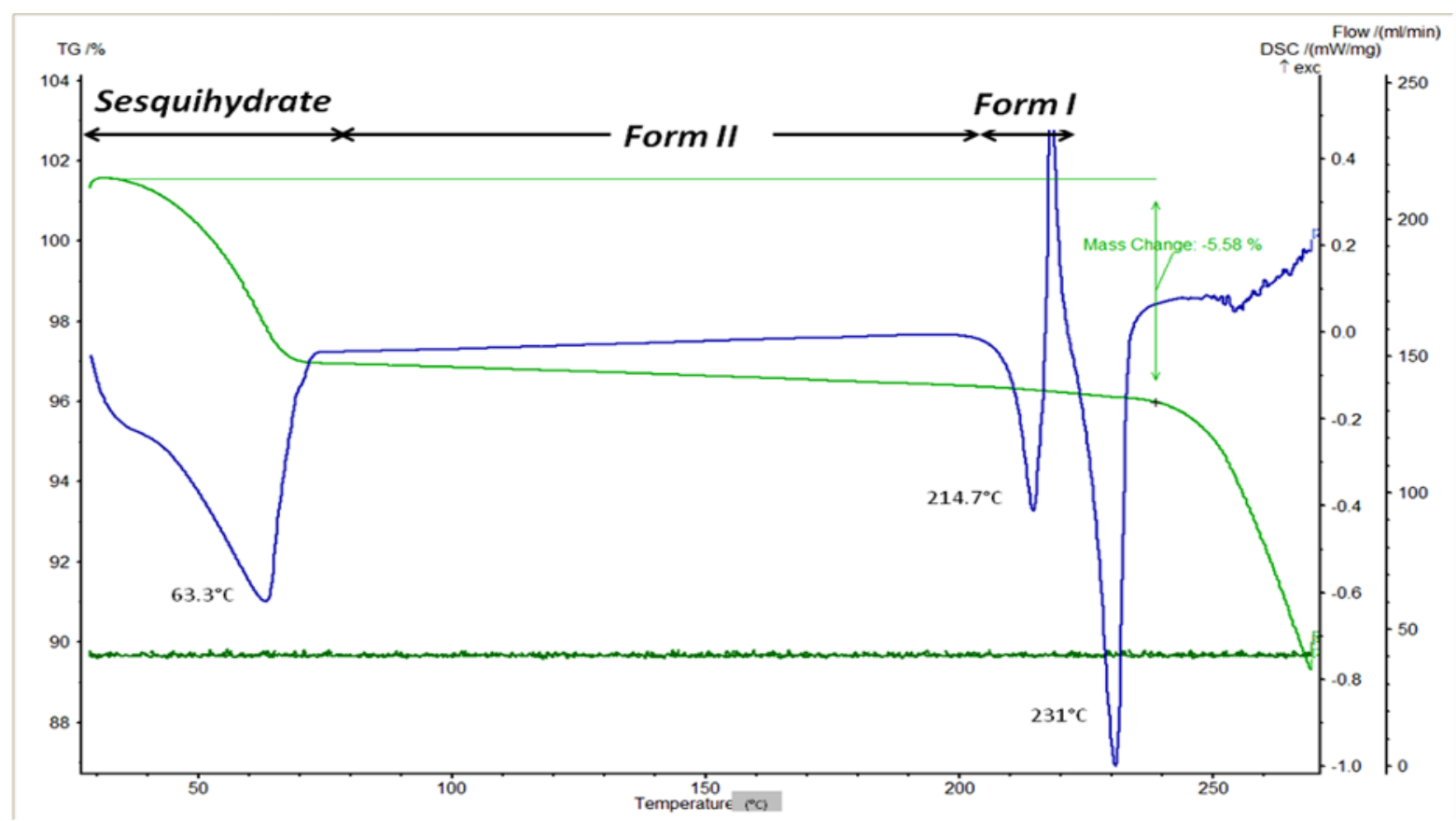

Figure 3. TG-DSC obtained on sesquihydrated phase of DMA.

\subsection{Behaviour under variable relative humidity.}

Form I is not sensitive to humidity variation. The transition between form II and sesquihydrate is reversible by increasing/decreasing relative humidity (figure 4). Moreover, no transition from sesquihydrate to monohydrate was recorded.
Under high relative humidity, the storage of monohydrate induces no transformation into sesquihydrate. In addition, the drying step on this phase leads to the formation of form II (consistent with thermal behavior) which transforms into sesquihydrate under high relative humidity. The drying step is irreversible as the monohydrate has never been obtained again (Figure 5). 


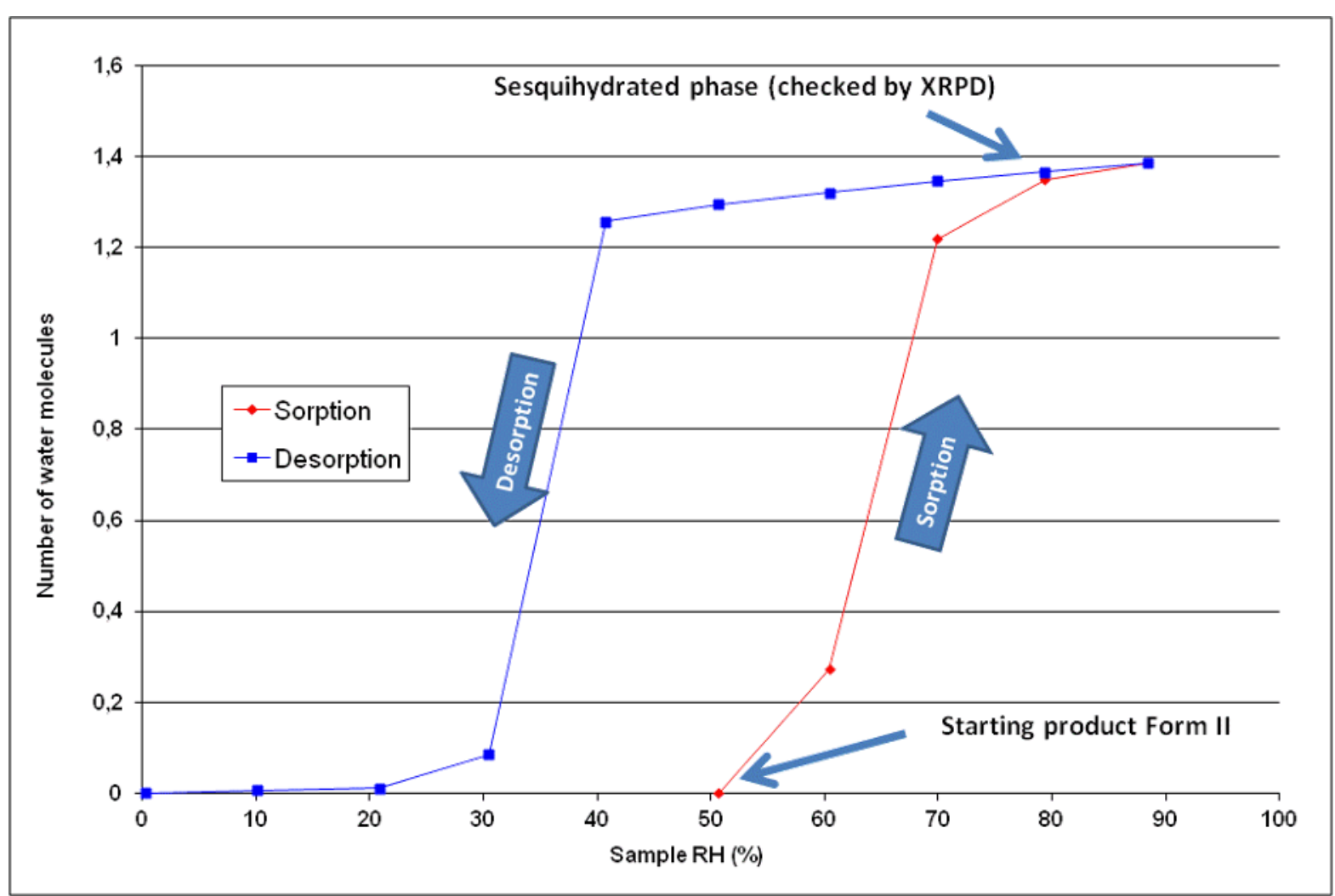

Figure 4. Isothermal $\left(20^{\circ} \mathrm{C}\right)$ sorption-desorption of the form II of DMA.

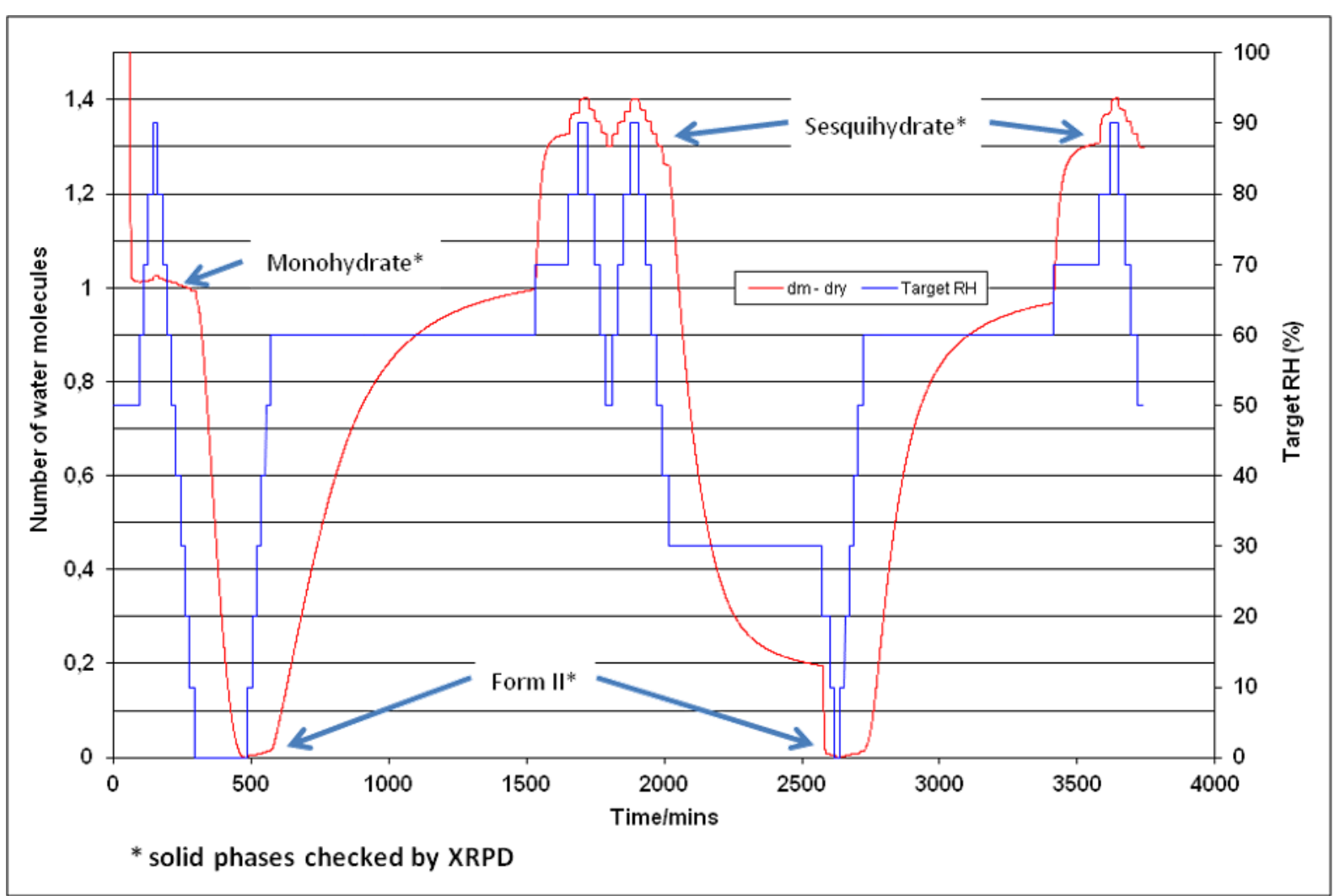

Figure 5. Mass variation recorded at $20^{\circ} \mathrm{C}$ for the DMA monohydrated phase submitted to variable relative humidity.

\subsection{Crystallographic structures}

Single crystals were obtained for: Form I, Monohydrate and sesquihydrate. During the resolution of crystallographic structures, no structural filiations were detected between these phases. This assumption is consistent with the behavior recorded under variable temperature and relative humidity. Unfortunately, we never succeed in obtaining single crystal of form II. 
Nevertheless, regarding to experimental data, one can assumed that a structural filiation could exist between form II and sesquihydrated phase.

\section{Conclusion}

By combining experimental information collected on DMA system in water it was possible to propose a stability chart of these solid phases (figure 6)

Therefore, Form II is a central phase in this system: it is metastable on a large range of temperature and can be easily accessible by dehydration (starting from other solvates also). A thorough description of its crystallographic structure seems to be the main challenge in order to understand completely the solid-solid transition and to propose mechanisms of whiskers formation.

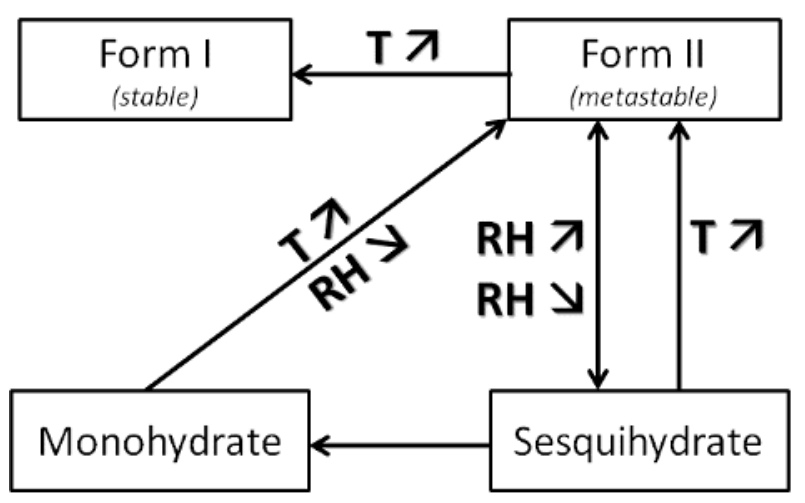

Figure 6. Stability chart of DMA versus temperature and variation of Relative Humidity.

\section{References}

1. F. Mallet, S. Petit, S. Lafont, P. Billot, D. Lemarchand, G. Coquerel. Cryst. growth and Design 4965 (2004)

2. S. Nordhoff, J. Ulrich, J. Therm. Anal. Cal. 57181 (1999)

3. G. Coquerel, M. Sanselme, A. Lafontaine, (2011) WO 136921.A1 [P], 2011-04-06

4. A. Lafontaine, M. Sanselme, Y. Cartigny, G. Coquerel, J. Therm. Anal. Cal. (2013), DOI 10.1007/s10973-012-2798-0

5. Y. Amharar, S. Petit, M. Sanselme, G. Coquerel, Cryst. Growth Des. 11 (6) 2453 (2011)

6. R. Rotival, Y. Cartigny, G. Coquerel, P. Négrier, Y. Corvis, P. Espeau (2010) 36th JEEP Proceedings, Montpellier France 